\title{
Sutureless replacement versus transcatheter valve implantation in aortic valve stenosis: A propensity-matched analysis of 2 strategies in high-risk patients
}

\author{
Giuseppe Santarpino, MD, ${ }^{\mathrm{a}}$ Steffen Pfeiffer, MD, ${ }^{\mathrm{a}}$ Jürgen Jessl, MD, ${ }^{\mathrm{b}}$ Angelo Maria Dell'Aquila, MD, \\ Francesco Pollari, MD, ${ }^{\mathrm{a}}$ Matthias Pauschinger, MD, ${ }^{\mathrm{b}}$ and Theodor Fischlein, $\mathrm{MD}^{\mathrm{a}}$
}

Objective: This propensity-matched study compared clinical and echocardiographic outcomes between patients undergoing transcatheter aortic valve implantation (TAVI) and sutureless aortic valve replacement.

\begin{abstract}
Methods: From January 2010 to March 2012, 122 patients (age $79.4 \pm 5.3$ years, logistic euroSCORE $12 \% \pm 8.4 \%$ ) underwent minimally invasive sutureless aortic valve replacement, and 122 (age $84.6 \pm 6.2$ years, logistic euroSCORE $20.9 \% \pm 2.5 \%$ ) underwent TAVI. After propensity matching, 37 matched pairs were available for analysis.
\end{abstract}

\begin{abstract}
Results: Preoperative characteristics and risk scores of matched groups were comparable. In-hospital mortalities were $0 \%$ in the sutureless group and $8.1 \%(\mathrm{n}=3)$ in the TAVI group $(P=.24)$. Permanent pacemaker implantation was required in 4 patients in the sutureless group and 1 patient in the TAVI group $(10.8 \%$ vs $2.7 \% ; P=.18)$. A neurologic event was recorded in 2 patients of each group. Predischarge echocardiographic data showed higher paravalvular leak rate in the TAVI group $(13.5 \%$ vs $0 \% ; P=.027)$. At mean follow-up of $18.9 \pm 10.1$ months, overall cumulative survival was $91.9 \%$ and significantly differed between groups (sutureless $97.3 \%$ vs TAVI $86.5 \% ; P=.015$ ). In the TAVI group, a significant difference in mortality was observed between patients with $(\mathrm{n}=20)$ and without $(\mathrm{n}=17)$ paravalvular leak $(25 \% \mathrm{vs} 0 \%$; $P=.036)$.
\end{abstract}

Conclusions: Combining the advantage of standard diseased valve removal with shorter procedural times, minimally invasive sutureless aortic valve replacement may be the first-line treatment for high-risk patients considered in the "gray zone" between TAVI and conventional surgery. (J Thorac Cardiovasc Surg 2014;147:561-7)

According to the recent guidelines of the European Society of Cardiology on the management of valvular heart disease, ${ }^{1}$ aortic valve replacement (AVR) is recommended as first-line therapy in patients with severe symptomatic aortic valve stenosis to improve both symptoms and survival. In the last few years, in particular after the publication of the Cohort A results of the PARTNER (Placement of AoRTic TraNscathetER Valve) trial, ${ }^{2}$ there has been great debate regarding alternative therapeutic

\footnotetext{
From the Department of Cardiac Surgery, ${ }^{a}$ Klinikum Nürnberg, Nürnberg, Germany; the Department of Cardiology, ${ }^{\mathrm{b}}$ Klinikum Nürnberg, Nürnberg, Germany; and the Department of Cardiac Surgery, ${ }^{c}$ Universitätsklinikum Münster, Münster, Germany.

Disclosures: S.P. is a proctor and T.F. is a consultant for Sorin Group Srl, Saluggia, Italy. All other authors have nothing to disclose with regard to commercial support. Read at the 39th Annual Meeting of The Western Thoracic Surgical Association, Coeur d'Alene, Idaho, June 26-29, 2013.

G.S. and S.P. contributed equally to this work

Received for publication May 23, 2013; revisions received Aug 18, 2013; accepted for publication Oct 12, 2013; available ahead of print Nov 25, 2013.

Address for reprints: Giuseppe Santarpino, MD, Klinik für Herzchirurgie, Klinikum Nürnberg Süd, Breslauer Strasse 201, 90471 Nuremberg, Germany (E-mail: g.santarpino@ libero.it).

$0022-5223 / \$ 36.00$

Copyright (c) 2014 by The American Association for Thoracic Surgery

http://dx.doi.org/10.1016/j.jtcvs.2013.10.025
}

strategies such as transcatheter aortic valve implantation (TAVI) for high-risk patients with symptomatic severe aortic valve stenosis. From the dualism between the surgical and transcatheter approaches, a new option has emerged: recent studies have demonstrated better clinical and cosmetic results with minimally invasive techniques for AVR versus conventional surgery. ${ }^{3}$ The drawback of minimally invasive surgery is that it generally requires longer crossclamp and operative times. This may expose patients to potential additive risks, especially if the procedure is performed by surgeons who are not experts or are still on the learning curve. Although there are no data supporting this observation, a high level of surgical skills is required for these procedures because of the increasing use of technology, and a learning curve is unavoidable. More recently, sutureless AVR devices have been developed that enable short procedural times and also easy implantation of the aortic valve prosthesis when using a minimally invasive surgical approach. ${ }^{4-7}$ In case of the Perceval S (Sorin Group Srl, Saluggia, Italy), this hybrid solution is somewhere between conventional surgical AVR, as it allows removal of the native diseased valve, and the transcatheter approach, as the bioprosthetic valve is mounted on an expandable stent fixed to the 


\section{Abbreviations and Acronyms \\ AVR = aortic valve replacement \\ $\mathrm{CABG}=$ coronary artery bypass grafting \\ CORONARY $=$ Coronary Artery Bypass Surgery \\ Off- or On-Pump Revascularization \\ Study \\ PARTNER = Placement of AoRTic \\ TraNscathetER Valve [trial] \\ TAVI = transcatheter aortic valve implantation \\ TRITON = Surgical Treatment of Aortic \\ Stenosis With a Next Generation \\ Surgical Aortic Valve [trial]}

aortic annulus without sutures. Although follow-up data are relatively short term, this implantation technique is reported to be associated with very short procedural times. ${ }^{8}$

The aim of this single-center study was to assess retrospectively and compare all consecutive patients who have undergone TAVI or minimally invasive sutureless AVR in the last 2 years at our Center, after careful evaluation by our multidisciplinary heart team including cardiologists, cardiac surgeons, and cardiac anesthesiologists. A propensity score analysis was used to create matched pairs comparable for perioperative risk.

\section{MATERIALS AND METHODS}

We collected data of all patients with the diagnosis of severe aortic valve stenosis with an indication for surgery in our center since 2010. Two specific programs were initiated in our institution at the same time: the first program was developed in collaboration between cardiologists and cardiac surgeons for the use of TAVI (Sapien and Sapien XT; Edwards Lifesciences Inc, Irvine Calif), whereas the second program involved use of the Perceval S sutureless prosthesis. Every week, during an interdepartmental conference, we evaluated all patients affected by severe aortic valve stenosis referred to our center from peripheral hospitals, private practices, or our emergency department, considering comorbidities and surgical risk to determine the best therapy. In all patients aged older than 65 years with an indication for isolated AVR considered candidates for surgery (irrespective of euroSCORE), a low frailty score (evaluated by clinical inspection and other factors not included in the euroSCORE or Society of Thoracic Surgeons scoring system, such as poor mobility, nonvascular degenerative neurologic diseases including Parkinson and Alzheimer diseases, home oxygen therapy, liver cirrhosis), and compatible echocardiographic findings (symmetric aortic annulus with a diameter 19-27 mm and a sinotubular junction/annulus ratio $<1.3$ ), a Perceval $\mathrm{S}$ sutureless valve was implanted earlier as part of a premarket study (Cavalier Study) and later (after European Community approval in 2011) as routine use. During the premarket study, patients also signed an additional informed consent for the experimental use of the new type of prosthesis (not yet CE mark approved). An informed consent for the use of personal data and follow-up contact was also signed by all patients. The study was approved by the local ethics committee.

All patients with frailty factors judged at very high surgical risk or with a logistic euroSCORE greater than $20 \%$ underwent a TAVI procedure as part of a multicenter registry (Source XT) for the use of the Sapien XT prosthesis. The transfemoral approach was considered as the first-line strategy, leaving the transapical approach in case of inadequate vascular access. Patients assigned to the TAVI strategy with concomitant coronary artery disease underwent coronary angioplasty with stent implantation before TAVI if the coronary anatomy seemed favorable. Conversely, patients with unsuitable coronary anatomy underwent combined sutureless AVR and coronary artery bypass grafting (CABG), except for 1 patient with isolated ostial right coronary artery lesion who underwent transaortic TAVI and off-pump CABG (Table 1). ${ }^{9}$ Patients with a bicuspid aortic valve were excluded from both sutureless and TAVI implantation.

After 2 years of extensive experience with both procedures, a total of 244 patients were operated on, equally distributed between the TAVI and sutureless groups $(\mathrm{n}=122 \mathrm{each})$. Patients of both groups were comparable for clinical and surgical characteristics, and a retrospective propensity score analysis was performed. For the matched pair samples, postoperative and follow-up clinical and echocardiographic data were obtained. All patients were followed up at our outpatient clinic and were evaluated clinically and by questionnaire to assess events between visits. In particular, the need for rehospitalization for cardiovascular of other causes was recorded. Prosthetic valve function was evaluated with transthoracic echocardiography. The presence of paravalvular regurgitation was defined according to current guidelines as none or trace, mild, moderate, or severe. ${ }^{10}$ All echocardiographic examinations were performed by either of 2 echocardiographists with a Philips iE33 ultrasound machine (Philips, Eindhoven, The Netherlands).

The Perceval implantation technique has been described previously. ${ }^{11}$ If associated CABG surgery had to be performed, distal coronary anastomoses preceded prosthesis implantation, and proximal surgical sutures either were performed during primary crossclamping, after tangential clamping of the ascending aorta, or were avoided completely if suitable. General anesthesia with endotracheal intubation was used in both groups. Our heart team prefers this technique because it allows performance of intraoperative transesophageal echocardiography. In patients undergoing TAVI by the transfemoral route, the endotracheal tube was removed immediately after the procedure if appropriate. In all other cases, patients were extubated in the intensive care unit. Transfemoral procedures were performed through a minimally invasive direct vascular access: the access site was chosen according to computed tomographic findings, size of the common femoral artery, amount of calcification of the vessel and iliac arteries, and tortuosity, or in selected cases with the Prostar percutaneous closure device (Abbott Vascular, Santa Clara, Calif). Before all TAVI procedures, the cardiac apex and intended optimal coaxial alignment were localized by transthoracic echocardiography. The surgical technique for positioning and deploying the Sapien XT valve prosthesis has been well described and standardized for both the transapical and transfemoral approaches. ${ }^{12,13}$

\section{Statistical Analysis}

Categoric variables were summarized as frequencies (\%), and continuous variables were summarized as mean $\pm \mathrm{SD}$. A propensity score matching (1:1) was performed to control selection bias as a result of nonrandom assignment to the groups. The propensity score was defined as the probability of receiving TAVI. This was estimated by means of a multivariate regression analysis. The following patient characteristics and major preoperative risk factors were entered into the model: age, sex, body surface area, logistic euroSCORE, previous cardiac surgery, hypertension, hyperlipidemia, left ventricular ejection fraction, renal disease, previous myocardial infarction, chronic obstructive pulmonary disease, peripheral vascular disease, and New York Heart Association functional class. Once the propensity score had been estimated for each subject, a receiver operating characteristic curve area proved the performance of the model (Figure 1). The $P$ value of the Hosmer-Lemeshow test was .016, and $\mathrm{C}$ statistic for the fitted logistic regression model was $0.8(P<.001)$, indicating that the model fitting was excellent. Pairs were generated with the 5:1 digit matching approach. 
TABLE 1. Preoperative characteristics of the study population

\begin{tabular}{|c|c|c|c|}
\hline Variable & $\begin{array}{c}\text { Sutureless } \\
\text { AVR }(n=122)\end{array}$ & $\begin{array}{c}\text { TAVI } \\
(\mathrm{n}=122) \\
\end{array}$ & $\begin{array}{c}P \\
\text { value } \\
\end{array}$ \\
\hline Age (y) & $79.5 \pm 5.4$ & $84.7 \pm 6.2$ & $<.001$ \\
\hline Male sex & $55(45.1 \%)$ & $49(40.2 \%)$ & .259 \\
\hline $\operatorname{BSA}\left(\mathrm{m}^{2}\right)$ & $1.8 \pm 0.21$ & $1.7 \pm 0.16$ & $<.001$ \\
\hline Diabetes & $31(25.4 \%)$ & $49(40.2 \%)$ & .013 \\
\hline NYHA functional class & $2.9 \pm 0.4$ & $3.0 \pm 0.5$ & .052 \\
\hline Renal insufficiency & $18(14.7 \%)$ & $20(16.4 \%)$ & .537 \\
\hline Logistic euroSCORE (\%) & $12 \pm 8.4$ & $20.9 \pm 2.5$ & .031 \\
\hline Previous cardiac surgery & $15(12.3 \%)$ & $23(18.9 \%)$ & .108 \\
\hline $\operatorname{LVEF}(\%)$ & $57.3 \pm 7.9$ & $56.3 \pm 14.9$ & .497 \\
\hline Pulmonary hypertension & $23(18.8 \%)$ & $47(38.5 \%)$ & .001 \\
\hline AS & $104(85.25 \%)$ & $110(90.16 \%)$ & \\
\hline Combined AS and AR & $18(14.75 \%)$ & $12(9.84 \%)$ & \\
\hline Associated CABG & $43(35.2 \%)$ & $1(0.8 \%)$ & .001 \\
\hline \multicolumn{4}{|l|}{ Surgical approach } \\
\hline Full sternotomy & $46(37.7 \%)$ & & \\
\hline Partial sternotomy & $73(59.8 \%)$ & & \\
\hline Right thoracotomy & $3(2.5 \%)$ & & \\
\hline Transapical & & $72(59 \%)$ & \\
\hline Transfemoral & & $49(40.2 \%)$ & \\
\hline Transaortic & & $1(0.8 \%)$ & \\
\hline Prosthesis size (mm) & $24.0 \pm 1.3$ & $24.8 \pm 1.9$ & $<.001$ \\
\hline Crossclamp time (min) & $43.3 \pm 18.4$ & & \\
\hline CPB time (min) & $73.4 \pm 23.1$ & & \\
\hline
\end{tabular}

Data are mean \pm SD or number and percentage. $A V R$, Aortic valve replacement; $T A V I$, transcatheter aortic valve implantation; $B S A$, body surface area; $N Y H A$, New York Heart Association; $L V E F$, left ventricular ejection fraction; $A S$, aortic stenosis; $A R$, aortic regurgitation; $C A B G$, coronary artery bypass grafting; $C P B$, cardiopulmonary bypass.

Finally, postoperative outcomes of the resulting 37 matched pairs of both groups (TAVI and sutureless) with the same propensity score were compared, including in-hospital and valve-related complications and survival. Normal distribution of data was assessed with the Shapiro-Wilk test. Continuous variables were compared by paired $t$ test and categoric

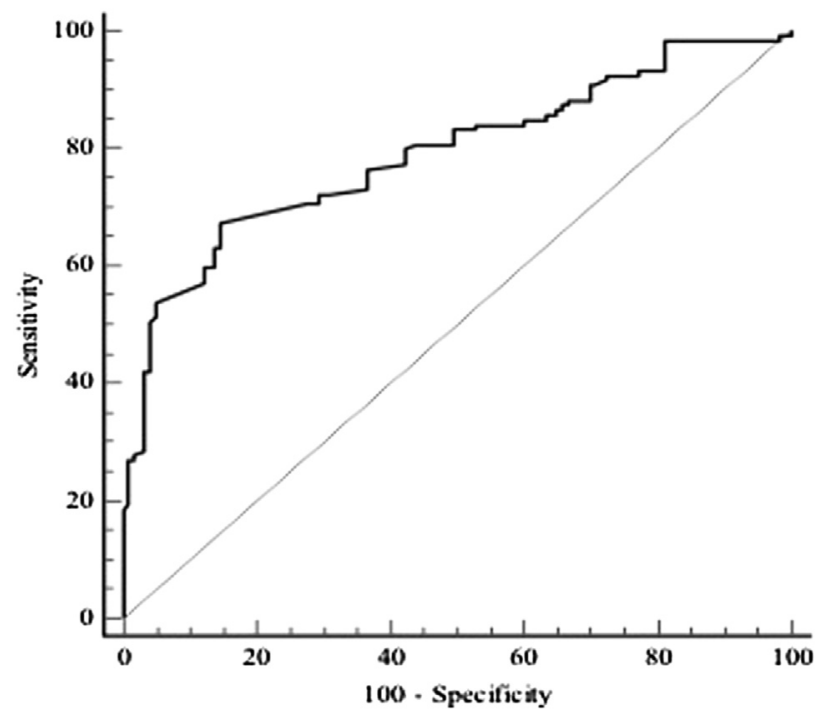

FIGURE 1. Receiver operating characteristic curve.
TABLE 2. Preoperative characteristics of the matched sutureless and transcatheter aortic valve implantation groups

\begin{tabular}{lccc}
\hline \multicolumn{1}{c}{ Variable } & $\begin{array}{c}\text { Sutureless } \\
\text { AVR }(\mathbf{n}=\mathbf{3 7})\end{array}$ & $\begin{array}{c}\text { TAVI } \\
(\mathbf{n = 3 7 )}\end{array}$ & $\begin{array}{c}\boldsymbol{P} \\
\text { value }\end{array}$ \\
\hline Age $(\mathrm{y})$ & $81.5 \pm 5.1$ & $84.5 \pm 5.1$ & .06 \\
Male sex & $15(40.5)$ & $18(48.6 \%)$ & .32 \\
BSA $\left(\mathrm{m}^{2}\right)$ & $1.7 \pm 0.2$ & $1.8 \pm 0.18$ & .3 \\
Logistic euroSCORE $(\%)$ & $18.1 \pm 1.9$ & $20.6 \pm 2.2$ & .81 \\
Redo procedure & $8(21.6 \%)$ & $8(21.6 \%)$ & .61 \\
Hypertension & $27(73 \%)$ & $22(59.5 \%)$ & .16 \\
Hyperlipidemia & $13(35.1 \%)$ & $17(45.9 \%)$ & .24 \\
LVEF $(\%)$ & $55.3 \pm 9.3$ & $55.4 \pm 14.6$ & .98 \\
Renal insufficiency & $5(13.5 \%)$ & $5(13.5 \%)$ & .61 \\
Previous myocardial infarction & $10(27 \%)$ & $14(37.8 \%)$ & .23 \\
COPD & $7(18.9 \%)$ & $12(32.4 \%)$ & .14 \\
Peripheral vascular disease & $5(13.5 \%)$ & $4(10.8 \%)$ & .5 \\
NYHA functional class & $2.97 \pm 0.5$ & $3.16 \pm 0.5$ & .13 \\
\hline D. &
\end{tabular}

Data are mean \pm SD or number and percentage. $A V R$, Aortic valve replacement; $T A V I$, transcatheter aortic valve implantation; $B S A$, body surface area; $L V E F$, left ventricular ejection fraction; $C O P D$, chronic obstructive pulmonary disease; NYHA, New York Heart Association.

variables by $\chi^{2}$ test. Cumulative survival curves were computed according to the Kaplan-Meier method. Survival curves and freedom from valve-related complications were compared with a Cox proportional hazards model stratified for the matched pairs.

\section{RESULTS}

Preoperative clinical and echocardiographic characteristics of the overall study population are reported in Table 1. Four patients underwent percutaneous transluminal coronary angioplasty with stent implantation before the TAVI procedure. Patients of the TAVI group were significantly older, had lower body surface area, and more often had diabetes or pulmonary hypertension. A higher proportion of patients in the sutureless group underwent associated CABG surgery, and they received a larger mean size prosthesis.

After propensity matching, 37 matched pairs were available for analysis. Preoperative clinical and echocardiographic characteristics of all matched pairs are reported in Table 2. Six patients in the TAVI matched group had undergone previous CABG surgery, and 1 had undergone percutaneous transluminal coronary angioplasty before the procedure. Two patients in the sutureless matched group had previously undergone CABG surgery. Eight patients in both groups underwent redo surgery. In the sutureless group, cardiopulmonary bypass and aortic crossclamping times were $68.9 \pm 20.2 \mathrm{~min}$ and $38.9 \pm 13.7 \mathrm{~min}$, respectively.

Postoperative outcomes are reported in Table 3. Although both groups had comparable body surface areas (Table 2), a larger prosthesis size was used in the TAVI group than in the sutureless group ( $25.3 \pm 2.1$ vs $24.2 \pm 1.13 \mathrm{~mm} ; P=.015)$. Despite this, no differences in postoperative mean transaortic gradient were observed $(14.2 \pm 5.8$ vs $13.3 \pm 3.9 \mathrm{~mm} \mathrm{Hg}$; 
TABLE 3. Postoperative outcomes of the matched sutureless and transcatheter aortic valve implantation groups

\begin{tabular}{lccc}
\hline \multicolumn{1}{c}{ Variable } & $\begin{array}{c}\text { Sutureless } \\
\text { AVR }(\mathbf{n}=\mathbf{3 7})\end{array}$ & $\begin{array}{c}\text { TAVI } \\
(\mathbf{n}=\mathbf{3 7})\end{array}$ & $\begin{array}{c}\boldsymbol{P} \\
\text { value }\end{array}$ \\
\hline In-hospital mortality & 0 & $3(8.1 \%)$ & .24 \\
ARF requiring CVVH & 0 & $2(5.4 \%)$ & .25 \\
Stroke & $2(5.4 \%)$ & $2(5.4 \%)$ & $>.999$ \\
Permanent PM implantation & $4(10.8 \%)$ & $1(2.7 \%)$ & .18 \\
Mean transaortic gradient (mm Hg) & $13.3 \pm 3.9$ & $14.2 \pm 5.8$ & .564 \\
AR at discharge (at least mild) & 0 & $5(13.5 \%)$ & .027 \\
\hline
\end{tabular}

$A V R$, Aortic valve replacement; TAVI, transcatheter aortic valve implantation $A R F$, acute renal failure; $C V V H$, continuous venovenous hemofiltration; $P M$, pacemaker; $A R$, aortic regurgitation.

$P=.564)$. At discharge, the incidence of aortic regurgitation caused by postprocedural paravalvular leakage was higher in the TAVI group than in the sutureless group $(13.5 \%$ vs $0 \%$; $P=.027)$.

Intraoperative complications occurred in 4 patients of the TAVI group (conversion to surgery with full sternotomy and conventional AVR as a result of valve dislocation in 2 , and need for mechanical resuscitation or emergency coronary stenting in 1 each) and in 3 patients of the sutureless group (1 bleeding requiring conversion to full sternotomy, 1 prosthesis explantation because of malpositioning with implantation of a stented prosthesis, and 1 postoperative bleeding necessitating reexploration; $P=.5$ ). Despite conversion, these patients were considered to be part of the original group enrolled and were included in the follow-up analysis. Three in-hospital deaths occurred in the TAVI group: of these, 1 was of septic shock and 2 of multiorgan failure (caused by liver insufficiency in 1 case and by respiratory insufficiency in the other). Permanent pacemaker implantation was required in 4 patients of the sutureless matched group and in 1 patient of the TAVI matched group $(10.8 \%$ vs $2.7 \% ; P=.18)$.

At a mean follow-up of $18.9 \pm 10.1$ months, the cumulative survival was $91.9 \%$ (Figure 2), with a significant difference between groups (sutureless vs TAVI, $97.3 \%$ vs $86.5 \% ; P=.015$ ). In the TAVI group, a significant difference in the mortality at follow-up was observed between patients with $(\mathrm{n}=20)$ and without $(\mathrm{n}=17)$ paravalvular leak $(25 \%$ vs $0 \% ; P=.036)$. When comparing the survival in the sutureless group $(\mathrm{n}=37,97.3 \%)$ with that of patients with no paravalvular leak in the TAVI group $(\mathrm{n}=17,100 \%)$, no significant differences were seen.

The cumulative freedom from rehospitalization was $70.3 \%(86.5 \%$ in the sutureless group and $54.1 \%$ in the TAVI group; $P=.054$ ). The overall freedom from neurologic events was $94.6 \%(97.3 \%$ in the sutureless group and $91.9 \%$ in the TAVI group; $P=.236$ ). There was a trend toward a higher rate of neurologic events in the TAVI group, although this did not reach statistical significance.

\section{DISCUSSION}

Our study compared 2 groups of patients undergoing sutureless AVR versus TAVI who were operated on by the same surgical team for both procedures. A propensitymatched analysis was used to generate 2 homogeneous groups with respect to preoperative characteristics and surgical risk. Our findings demonstrate that minimally invasive surgery is associated with similar in-hospital outcomes but lower paravalvular leak and mortality than is TAVI. In addition, the lower rate of postoperative paravalvular leak seems to result in a higher freedom from rehospitalization.

In the PARTNER trial, paravalvular regurgitation was more frequent after TAVI and was associated with increased late mortality. ${ }^{14} \mathrm{~A}$ significant difference in the 2-year mortality was reported between patients with mild to severe paravalvular leak and patients without or with only trace paravalvular leak. Notably, paravalvular aortic regurgitation occurred in approximately $40 \%$ of patients. In our study population, paravalvular leakage was common in the TAVI group and was associated with increased mortality and rehospitalization rate during follow-up relative to patients with no or minimal leakage or to those who had undergone sutureless AVR.

Conventional surgical AVR is associated with reduced rates of paravalvular regurgitation. In the study of Sponga and colleagues, ${ }^{15} 4.2 \%$ of patients were found to have paravalvular leak, and long-term survival was more negatively affected by the presence of significant residual aortic regurgitation ( $\geq 1 / 4$ grade).

From a theoretic point of view, the sutureless valve implantation technique might be expected to be associated with higher rates of paravalvular leakage because of the absence of active fixation of the prosthetic valve to the native aortic annulus. Previous studies on sutureless aortic valves, however, showed very low rates of paravalvular leakage, which were similar to the reported rates observed with standard models. In a multicenter study including patients from 10 European referral centers, sutureless AVR with the Enable bioprosthesis (Medtronic, Inc, Minneapolis, Minn) was associated with a $2.1 \%$ rate of major paravalvular leaks [4]. More recently, in the TRITON study, ${ }^{5}$ the 1 -year clinical outcome of AVR with the sutureless Edwards Intuity prosthesis demonstrated a paravalvular leak rate of $2.3 \%(1.4 \%$ and $0.9 \%$ for early and late occurrences, respectively). The Perceval $\mathrm{S}$ sutureless bioprosthesis, which we adopted, overall showed a slightly worse performance relative to other models. In a series of high-risk patients who received a Perceval bioprosthesis in 2 European centers, 9 patients $(4 \%)$ required reoperation for paravalvular regurgitation 


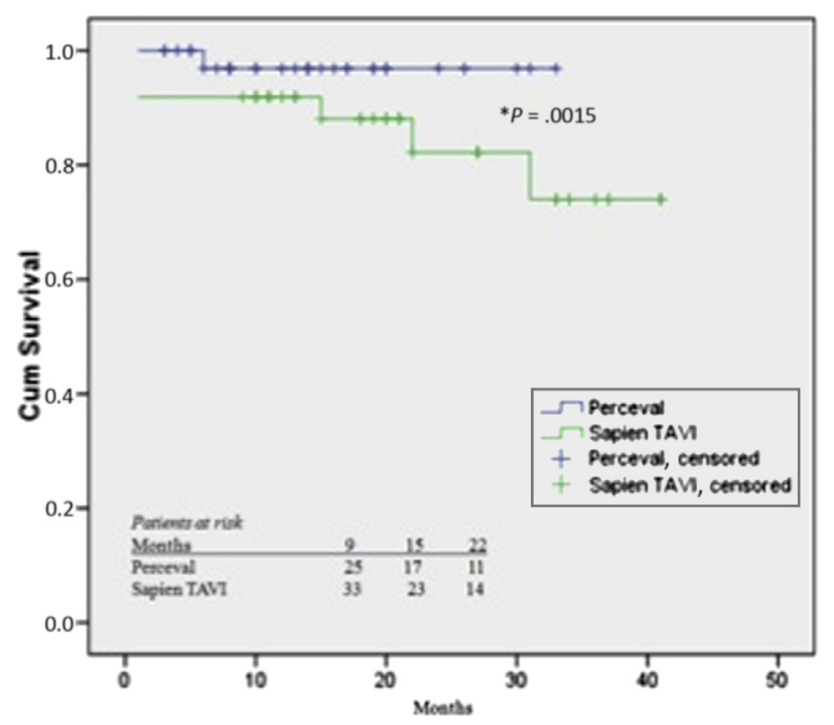

FIGURE 2. Kaplan-Meier survival curve. TAVI, Transcatheter aortic valve implantation; Cum, cumulative.

during follow-up. ${ }^{6}$ D'Onofrio and associates ${ }^{16}$ compared clinical and echocardiographic outcomes of patients undergoing transapical implantation of a Sapien prosthesis with those of patients undergoing AVR with the sutureless Perceval S aortic valve. Although data showed that the rate of paravalvular leak was greater in the TAVI group, it was as high as $15.8 \%$ in the AVR group.

After propensity score matching, no patient in our AVR group demonstrated paravalvular leak; however, the rate of paravalvular leak reached $1.6 \%(n=2)$ when the overall group of 122 patients in the sutureless group was considered. The main reason for the remarkable difference between our findings and those of D'Onofrio and associates $^{16}$ and the Paris and Hannover experience ${ }^{6}$ may be related to the aortic valve and annulus decalcification technique. As recommended by the manufacturer, the Perceval $\mathrm{S}$ requires no aggressive decalcification of the native valve, which is left in situ (similar to a TAVI procedure), and only excess calcific debris that would result in asymmetric annular dilatation is removed. In the 2 previously mentioned studies, it seems that the aortic annulus was only mildly decalcified. With the exception of the very first cases, a moderate decalcification of the aortic annulus is performed routinely at our center. At this stage, however, any hypothesis regarding the effect of decalcification on residual paravalvular leakage remains speculative, and other factors may play a significant role (eg, asymmetric bicuspid aortic valve). Notwithstanding this, moderate decalcification resulted in low rates of paravalvular leakage, and thus better long-term outcomes, in our study patients. A larger prosthesis size, however, was used in the TAVI group than in the sutureless group. It is well known that prosthesis size is not directly comparable across manufacturers, even in cases of equivalent nominal size. In addition, both Sapien and Perceval are self-expanding prostheses, and accurate measurement of diameter thus is not feasible. In this respect, measurement of the effective orifice area or the mean transaortic gradient may be more reliable, as evidenced by lack of differences in postoperative transaortic gradient reported in our study (14.2 \pm 5.8 vs $13.3 \pm 3.9 \mathrm{~mm} \mathrm{Hg} ; P=.564)$. Not surprisingly, the manufacturer of the Perceval $\mathrm{S}$ no longer provides prosthesis size in millimeters but marks them as small, medium, large, and extra large.

A direct comparison between conventional surgical AVR and TAVI was performed in cohort A of the PARTNER study. $^{2}$ No definitive data regarding the indications for conventional AVR or TAVI in high-risk patients could be derived, however, also because of the intrinsic limitations that exist in sponsored research studies. In addition, the noninferiority statistical approach and the intention-to-treat analysis included patients who refused the surgical option, thus affecting the results of treatment outcome. Accordingly, further studies are warranted to clarify this topic. Several investigations have also directly or indirectly shown the superiority of the minimally invasive approach relative to conventional surgical AVR. In the study by Johnston and coworkers, ${ }^{3}$ aortic valve surgery through an upper J sternotomy not only had cosmetic advantages relative to full sternotomy but also improved respiratory mechanics. Isolated AVR can also be performed through an anterolateral thoracotomy, which does not require a standard full incision and does not interrupt the osseous continuity of the chest, allowing even better respiratory mechanics. Glauber and colleagues ${ }^{17}$ compared this approach with standard median sternotomy by means of a propensity score analysis and showed that avoiding median sternotomy improves the clinical outcome, with lower incidences of postoperative atrial fibrillation and blood transfusion and shorter ventilation time and hospital stay. The policy at our institution is to perform isolated AVR through a minimally invasive approach routinely with a J sternotomy or anterolateral thoracotomy according to the position of the ascending aorta at the level of the pulmonary artery bifurcation on chest computed tomography. ${ }^{18}$ Whether this surgical strategy has a favorable impact on clinical outcome as compared to TAVI remains to be clearly elucidated; it goes beyond the scope of this study.

In their comparative study of TAVI versus minimally invasive Perceval implantation with propensity score matching, D'Onofrio and associates ${ }^{16}$ included only patients undergoing TAVI through a transapical approach. As may be inferred from the discussion at the 92nd American Association for Thoracic Surgery annual meeting, the reasons for this patient selection are related to the fact that data regarding transfemoral TAVI were collected by cardiologists rather than by cardiac surgeons. We do agree with those authors on the need for studies 
evaluating the "gray zone" of patients for whom the indications for TAVI versus surgical AVR is still unclear, but we also believe that all TAVI approaches should be assessed as a whole to be much closer to "real world" patient populations. Accordingly, in our study no patients were excluded from propensity score matching: the TAVI group included patients who had undergone a transcatheter procedure for AVR through either transfemoral or transapical access, transaortic TAVI with associated CABG, or valve-in-valve implantation in the aortic position. Only patients undergoing valve-in-valve implantation in the mitral position were excluded. The sutureless group included patients who had undergone minimally invasive AVR either isolated or associated with $\mathrm{CABG}$ through a full sternotomy. We also included patients who had undergone combined CABG and Perceval S implantation, because it is likely that with the use of a heart team approach the feasibility of transaortic TAVI associated with on- or off-pump CABG will be considered increasingly often. Although few data in the literature are available except for isolated case reports, ${ }^{19}$ this option seems a valid alternative within the development of a hybrid revascularization program,${ }^{20}$ allowing performance of TAVI and myocardial revascularization without cardiopulmonary bypass in the growing population of patients with aortic valve disease associated with coronary artery disease (coexisting in as many as $75 \%$ of patients according to the Dallas group ${ }^{21}$ ).

Current recommendations suggest performance of associated $\mathrm{CABG}$ only in patients undergoing conventional surgical AVR, whereas TAVI should be considered in patients at high risk (Society of Thoracic Surgeons score $>8$ ) or with prohibitive surgical risk but favorable valve anatomy. ${ }^{22}$

The major interest in the TAVI procedure is based on the possibility of avoiding cardiopulmonary bypass. It is well known that removal of the diseased valve-infeasible with the transcatheter approach-results in lower rates of paravalvular leak, which is likely among the major determinants of stroke after TAVI. No evidence so far, however, supports the hypothesis that avoidance of cardiopulmonary bypass confers any benefits. A similar debate is currently taking place regarding the use of off-pump versus on-pump CABG. The results of the ongoing CORONARY (Coronary Artery Bypass Surgery Off- or OnPump Revascularization Study) trial will clarify these issues. A few years ago, the same lively debate surrounded the initial enthusiasm for coronary stents, which were supposed to replace cardiac surgery in the near future; however, current data still strongly support cardiac surgery. ${ }^{23}$

\section{Study Limitations}

Propensity score matching has allowed comparison between groups without differences in the distribution of preoperative characteristics, but at the expense of the sample size (only 37 patients for each group). This is the most important limitation of our study. The decision to proceed with surgical AVR or TAVI was based on the clinical judgment of the heart team, because this multidisciplinary approach is key to procedural success, and on the evaluation of the frailty score by clinical inspection. Our propensity score was based on traditional risk factors, and frailty was not considered in the pair matching because it could represent a potential bias.

In 2010, the TAVI and sutureless programs were initiated simultaneously at our institution, and the different learning curves associated with the techniques may have played a role. Although the difference is difficult to quantify, especially in relatively small sample sizes, we might speculate that in the setting of a cardiac surgical team the learning curve was faster and easier for sutureless AVR than for TAVI. Sutureless AVR is quite similar to conventional surgical AVR, whereas TAVI is a more difficult procedure that requires a longer learning curve. Both types of surgical procedure were performed with the assistance of a proctor, however, who left our center only after the learning curve was completed.

Different surgical access routes were used in the study groups (full sternotomy and $\mathrm{J}$ ministernotomy for sutureless AVR and transfemoral and transapical approaches for TAVI). The small sample size, however, did not allow subgroup analysis.

Finally, the relatively short follow-up (mean 18 months) represents another study limitation.

\section{CONCLUSIONS}

In conclusion, removal of the diseased native valve may enhance procedural quality by avoiding paravalvular leak. In combination with minimally invasive sutureless AVR, this may become the first-line treatment for high-risk patients considered in the gray zone between TAVI and conventional surgery. Further larger, prospective, randomized studies are warranted to confirm our results.

The authors thank Joachim Schidt, MD, and Ferdinand Vogt, $\mathrm{MD}$, for their support in performing the echocardiographic examinations.

\footnotetext{
References

1. Vahanian A, Alfieri O, Andreotti F, Antunes MJ, Barón-Esquivias G, Baumgartner H, et al. Guidelines on the management of valvular heart disease (version 2012): the Joint Task Force on the Management of Valvular Heart Disease of the European Society of Cardiology (ESC) and the European Association for Cardio-Thoracic Surgery (EACTS). Eur J Cardiothorac Surg. 2012;42:S1-44.

2. Reynolds MR, Magnuson EA, Wang K, Thourani VH, Williams M, Zajarias A, et al, PARTNER Trial Investigators. Health-related quality of life after transcatheter or surgical aortic valve replacement in high-risk patients with severe aortic stenosis: results from the PARTNER (Placement of AoRTic TraNscathetER Valve) Trial (Cohort A). J Am Coll Cardiol. 2012;60: 548-58.

3. Johnston DR, Atik FA, Rajeswaran J, Blackstone EH, Nowicki ER, Sabik JF III, et al. Outcomes of less invasive J-incision approach to aortic valve surgery. J Thorac Cardiovasc Surg. 2012;144:852-8.e3.
} 
4. Martens S, Sadowski J, Eckstein FS, Bartus K, Kapelak B, Sievers HH, et al. Clinical experience with the ATS $3 f$ Enable ${ }^{\circledR}$ Sutureless Bioprosthesis. Eur J Cardiothorac Surg. 2011;40:749-55.

5. Kocher AA, Laufer G, Haverich A, Shrestha M, Walther T, Misfeld M, et al. One-year outcomes of the Surgical Treatment of Aortic Stenosis With a Next Generation Surgical Aortic Valve (TRITON) trial: a prospective multicenter study of rapid-deployment aortic valve replacement with the EDWARDS INTUITY Valve System. J Thorac Cardiovasc Surg. 2013;145:110-5; discussion 115-6.

6. Folliguet TA, Laborde F, Zannis K, Ghorayeb G, Haverich A, Shrestha M. Sutureless Perceval aortic valve replacement: results of two European centers. Ann Thorac Surg. 2012;93:1483-8.

7. Santarpino G, Pfeiffer S, Schmidt J, Concistrè G, Fischlein T. Sutureless aortic valve replacement: first-year single-center experience. Ann Thorac Surg. 2012; 94:504-8; discussion 508-9.

8. Flameng W, Herregods MC, Hermans H, Van der Mieren G, Vercalsteren M, Poortmans G, et al. Effect of sutureless implantation of the Perceval S aortic valve bioprosthesis on intraoperative and early postoperative outcomes. J Thorac Cardiovasc Surg. 2011;142:1453-7.

9. Santarpino G, Pfeiffer S, Fischlein T. Off-pump coronary artery bypass grafting in combination with transaortic transcatheter aortic valve implantation: a possible approach for patients with associated diseases. Int J Cardiol. 2012;157:e7-8.

10. Zoghbi WA, Chambers JB, Dumesnil JG, Foster E, Gottdiener JS, Grayburn PA, et al., American Society of Echocardiography's Guidelines and Standards Committee; Task Force on Prosthetic Valves; American College of Cardiology Cardiovascular Imaging Committee; Cardiac Imaging Committee of the American Heart Association; European Association of Echocardiography; European Society of Cardiology; Japanese Society of Echocardiography; Canadian Society of Echocardiography; American College of Cardiology Foundation; American Heart Association; European Association of Echocardiography; European Society of Cardiology; Japanese Society of Echocardiography; Canadian Society of Echocardiography. Recommendations for evaluation of prosthetic valves with echocardiography and Doppler ultrasound: a report from the American Society of Echocardiography's Guidelines and Standards Committee and the Task Force on Prosthetic Valves, developed in conjunction with the American College of Cardiology Cardiovascular Imaging Committee, Cardiac Imaging Committee of the American Heart Association, the European Association of Echocardiography, a registered branch of the European Society of Cardiology, the Japanese Society of Echocardiography and the Canadian Society of echocardiography, endorsed by the American College of Cardiology Foundation, American Heart Association, European Association of Echocardiography, a registered branch of the European Society of Cardiology, the Japanese Society of Echocardiography, and Canadian Society of Echocardiography. J Am Soc Echocardiogr. 2009;22:975-1014; quiz 1082-4.

11. Santarpino G, Pfeiffer S, Concistrè G, Fischlein T. Perceval S aortic valve implantation in mini-invasive surgery: the simple sutureless solution. Interact Cardiovasc Thorac Surg. 2012;15:357-60.

12. Walther T, Möllmann H, van Linden A, Kempfert J. Transcatheter aortic valve implantation transapical: step by step. Semin Thorac Cardiovasc Surg. 2011; 23:55-61.
13. Willson A, Toggweiler S, Webb JG. Transfemoral aortic valve replacemen with the SAPIEN XT valve: step-by-step. Semin Thorac Cardiovasc Surg. 2011; 23:51-4.

14. Kodali SK, Williams MR, Smith CR, Svensson LG, Webb JG, Makkar RR, et al., PARTNER Trial Investigators. Two-year outcomes after transcatheter or surgical aortic-valve replacement. $N$ Engl J Med. 2012;366:1686-95.

15. Sponga S, Perron J, Dagenais F, Mohammadi S, Baillot R, Doyle D, et al. Impact of residual regurgitation after aortic valve replacement. Eur J Cardiothorac Surg. 2012;42:486-92.

16. D’Onofrio A, Messina A, Lorusso R, Alfieri OR, Fusari M, Rubino P, et al Sutureless aortic valve replacement as an alternative treatment for patients belonging to the "gray zone" between transcatheter aortic valve implantation and conventional surgery: a propensity-matched, multicenter analysis. J Thorac Cardiovasc Surg. 2012;144:1010-6.

17. Glauber M, Miceli A, Gilmanov D, Ferrarini M, Bevilacqua S, Farneti PA, et al. Right anterior minithoracotomy versus conventional aortic valve replacement: a propensity score matched study. J Thorac Cardiovasc Surg. 2013;145:1222-6.

18. Glauber M, Miceli A, Bevilacqua S, Farneti PA. Minimally invasive aortic valve replacement via right anterior minithoracotomy: early outcomes and midterm follow-up. J Thorac Cardiovasc Surg. 2011;142:1577-9.

19. Wiegerinck EM, Cocchieri R, Baan J Jr, de Mol BA. Hybrid coronary artery bypass grafting and transaortic transcatheter aortic valve implantation. J Thorac Cardiovasc Surg. 2013;145:600-2.

20. Unbehaun A, Pasic M, Dreysse S, Buz S, Kukucka M, Hetzer R, et al Transcatheter aortic valve implantation and hybrid coronary artery revascularization: time to combine them. Innovations (Phila). 2011;6:395-8.

21. Dewey TM, Brown DL, Herbert MA, Culica D, Smith CR, Leon MB, et al Effect of concomitant coronary artery disease on procedural and late outcomes of transcatheter aortic valve implantation. Ann Thorac Surg. 2010;89:758-67; discussion 767.

22. Holmes DR Jr, Mack MJ, Kaul S, Agnihotri A, Alexander KP, Bailey SR, et al. American College of Cardiology Foundation; American Association for Thoracic Surgery; Society for Cardiovascular Angiography and Interventions; Society for Thoracic Surgeons; American Heart Association; American Society of Echocardiography; European Association for Cardio-Thoracic Surgery; Heart Failure Society of America; Mended Hearts; Society of Cardiovascular Anesthesiologists; Society of Cardiovascular Computed Tomography; Society for Cardiovascular Magnetic Resonance. 2012 ACCF/AATS/SCAI/STS expert consensus document on transcatheter aortic valve replacement: developed in collaboration with the American Heart Association, American Society of Echocardiography, European Association for Cardio-Thoracic Surgery, Heart Failure Society of America, Mended Hearts, Society of Cardiovascular Anesthesiologists, Society of Cardiovascular Computed Tomography, and Society for Cardiovascular Magnetic Resonance. Ann Thorac Surg. 2012;93: 1340-95.

23. Serruys PW, Morice MC, Kappetein AP, Colombo A, Holmes DR, Mack MJ et al., SYNTAX Investigators. Percutaneous coronary intervention versus coronary-artery bypass grafting for severe coronary artery disease. $N$ Engl J Med. 2009;360:961-72. 